\title{
REVESTINDO O CAMINHO DO SERVICO AO CLIENTE POR MEIO DA LOGÍSTICA: O CASO DA PORTOBELLO SHOP
}

IMPROVING CUSTOMER SERVICE THROUGH LOGISTS: THE CASE OF THE PORTOBELLO SHOP REVISTIENDO EL CAMINO DEL SERVICIO AL CLIENTE POR MEDIO DE LA LOGÍSTICA: EL CASO DE LA PORTOBELLO SHOP

Helena Regina Battistotti

Especialista

helenar@portobello.com.br

Carlos Marcelo Ardigó

Doutorando

Universidade do Vale do Itajaí

marcelo.ardigo@univali.br

Olga Regina Cardoso

Doutora

Universidade Federal de Santa Catarina

cardosoolga@uol.com.br

Submetido em: 29/07/2013

Aprovado em: 16/12/2013

RESUMO

Na empresa Portobello, organização foco deste relato, a logística representa um importante elo da cadeia de valor. Por esta razão, o monitoramento e a avaliação contínua do desempenho dos processos e definição de indicadores chaves tornam-se vitais. No caso específico da unidade de negócio investigada, a Portobello Shop, a operação logística vem trabalhando na busca de alto padrão de atendimento e distribuição diferenciados de acordo com o posicionamento desejado para o negócio. Por meio da implantação e do reconhecimento desses indicadores, os gestores podem avaliar o desempenho e adotar estratégias a fim de mitigar os custos e aperfeiçoar sua eficiência logística, atendendo da melhor forma as exigências de seus clientes. Neste contexto, a logística exerce um decisivo papel para a obtenção de vantagens competitivas perante a concorrência, e a busca pelo alto desempenho do indicador OTIF se torna um desafio. O presente trabalho examinou a abordagem logística atual e promoveu reflexões voltadas para as situações enfrentadas na operação da Portobello Shop, de forma a contribuir para o planejamento estratégico da empresa, apoiando o posicionamento organizacional voltado ao alcance da alta confiabilidade junto ao mercado.

PALAVRAS-CHAVE: Gestão logística. Serviço ao cliente. On Time In Full (OTIF).

ABSTRACT

At the company Portobello, the organization that is the focus of this report, logistics represents an important link in the value chain. For this reason, continuous monitoring and evaluation of the performance of processes, and establishing keys indicators, are vital. In the specific case of the business studied, the Portobello Shop, the logistics operation has been working to provide a high standard of differentiated 
services and distribution, according to the desired positioning for the business. Through the implementation and recognition of these indicators, managers can assess performance and adopt strategies in order to mitigate costs and improve the company's logistics efficiency, seeking to better meet customers' demands. In this context, logistics plays a decisive role in gaining competitive advantage, and the search for high performance of the On Time In Full (OTIF) indicator becomes a challenge. This work examines the current logistics approach and promotes reflection on the situations faced in the operation of the Portobello shop, seeking to contribute to the company's strategic planning, and supporting the organization's search to win the trust of the market.

KEYWORDS: Logistics management. Customer services. On time in full (OTIF).

\section{RESUMEN}

En la empresa Portobello, organización foco de este relato, la logística representa un importante eslabón de la cadena de valor. Por esta razón resulta vital el monitoreo y la evaluación continua del desempeño de los procesos y la definición de indicadores clave. En el caso específico de la unidad de negocio investigada, la Portobello Shop, la operación logística viene trabajando en la búsqueda de alto nivel de atención y distribución diferenciados de acuerdo con el posicionamiento deseado para el negocio. Por medio de la implantación y del reconocimiento de estos indicadores, los gestores pueden evaluar el desempeño y adoptar estrategias a fin de mitigar los costos y perfeccionar su eficiencia logística, atendiendo de la mejor forma posible las exigencias de sus clientes. En este contexto, la logística ejerce un decisivo papel para la obtención de ventajas competitivas frente a la competencia, y la búsqueda de alto desempeño del indicador OTIF se vuelve un desafío. El presente trabajo examinó el abordaje logístico actual y promovió reflexiones dirigidas a las situaciones enfrentadas en la operación de la Portobello Shop para contribuir con el planeamiento estratégico de la empresa, apoyando el posicionamiento organizacional dirigido al logro de la alta confiabilidad en el mercado.

PALABRAS ClAVE: Gestión logística. Servicio al cliente. On Time In Full (OTIF).

\section{INTRODUÇÃO}

Com a globalização, acentuada no mercado brasileiro pelas políticas cambiais que privilegiam importação, maior diversidade de oferta e consumidores mais exigentes, uma nova dinâmica competitiva vem se estabelecendo. Essa grande mudança e as constantes exigências estão fazendo com que as empresas se obriguem constantemente, mediante passaporte para suas permanências no mercado, a agregar valor ao que oferece. Pode-se dizer que qualidade é uma commodity, ou seja, um padrão. Ou se tem qualidade ou o mercado está de costas para você. É nesse contexto que as empresas buscam um diferencial competitivo e apostam suas fichas cada vez mais nos serviços. Entre eles o serviço logístico de valor agregado.

A Portobello S.A vem construindo esse diferencial em várias de suas decisões estratégicas, entre elas a determinação de um canal de distribuição exclusivo: as franquias. O grupo detém a única rede de franquias do Brasil, a Portobello Shop, direcionada exclusivamente para revestimento cerâmico, trazendo para o mercado um novo conceito, em que além de uma linha exclusiva de produtos de alta qualidade, oferece aos clientes atendimento personalizado por arquitetos, engenheiros e designers. O foco é prestar serviços que auxiliem no momento da decisão e facilitem o desenvolvimento da obra, com o intuito de levar o consumidor a uma ótima experiência de compra.

Para sustentar esta proposta audaciosa, a Portobello Shop investiu em uma grande estrutura de logística, para viabilizar que seus produtos pudessem ser entregues em qualquer loja do país, ou, inclusive, diretamente na casa do consumidor final, em pallets elaborados de forma personalizada para o canal, denominada: "Pallets Solução". O propósito é atender às necessidades individuais de 
seus clientes finais também no que se refere à distribuição física. A proposta da Portobello Shop é de que o cliente compre somente a quantidade específica que necessita de um determinado produto, mesmo que esta quantidade seja menor do que uma caixa, ou até mesmo uma única peça de revestimento, customizando assim seu projeto de arquitetura.

Adotando este modelo, o grupo Portobello manda a mensagem clara de que a qualidade do seu produto cerâmico já não é mais a única determinante do sucesso nesse mercado. Tendo essa visão, a Portobello Shop busca, por meio de controle e melhores práticas na sua competência logística, aumentar a confiabilidade perante seus clientes e, para isso, inseriu em suas metas a busca pelo On Time In Full, que conceitualmente seria a qualidade do serviço logístico, por meio do qual, na primeira remessa, atendem-se as necessidades acordadas com o cliente entregando no tempo prometido, a solicitação completa e sem erros.

No caso específico da Portobello Shop isto poderia ser interpretado como aquele entregue no lugar certo, no dia certo, com todas as suas características corretas, como tamanho, cor, quantidade, nota fiscal, entre outros. Sabe-se que, para isso, muitos detalhes devem ser analisados: os indicadores de desempenhos mensurados de forma correta e deve se estabelecer uma metodologia de gestão e prevenção dos desvios das metas. Assim, a finalidade da logística está em entregar o produto certo, na hora certa, nas condições físicas desejadas ao menor custo possível.

Na sequência do relato deste caso, segue um panorama do mercado cerâmico brasileiro, sua situação doméstica e aspectos do mercado internacional, incluindo o ambiente competitivo. Também são destaques aspectos do ambiente interno organizacional, especificamente aqueles relacionados ao setor logístico da empresa foco e que complementam o desafio dos gestores ligados a essa área funcional.

\section{O MERCADO CERÂMICO BRASILEIRO}

O crescimento e o desenvolvimento de um país condicionam uma série de setores a um processo de expansão. O Brasil e o setor cerâmico são um exemplo dessa correlação. O país em 2011 chegou à posição de $6^{\circ}$ maior economia mundial com Produto Interno Bruto (PIB) de mais de $\mathrm{R} \$ 4,1$ trilhões. Isso demonstra que, apesar do crescimento de apenas 2,7\% comparado a 2010, mesmo com a crise mundial, o Brasil continuou crescendo (BRASIL, 2012). A construção civil, por sua vez, continua sendo um dos líderes do atual padrão do crescimento econômico do Brasil. O bom momento econômico ajudou a alavancar o setor por meio de grandes investimentos na construção de moradias, ampliação da demanda imobiliária, e grandes obras que a Copa do Mundo de 2014 e as Olimpíadas de 2016 irão demandar. E com toda essa movimentação do setor, o governo se posiciona para divulgar investimentos em infraestrutura e melhorias em todas as regiões, incluindo estradas, habitação, aeroportos e outros setores que precisam de investimentos imediatos.

Segundo a Associação Brasileira da Indústria de Materiais de Construção (ABRAMAT, 2011) o resultado das vendas internas deflacionadas de materiais de construção, acumulado de Janeiro a Setembro de 2011, apresentou crescimento de 2,2\% em relação ao resultado do mesmo período de 2010. Este resultado sugere crescimento abaixo da previsão para 2011 que é de $5 \%$ de crescimento em relação ao ano passado, porém vem sendo observada uma tendência de recuperação nos últimos meses. As expectativas do setor para o próximo trimestre estão otimistas, apoiadas na continuidade da elevada disponibilidade de crédito e do elevado nível de emprego no mercado e na continuidade da desoneração do IPI dos materiais até 2012. Podese visualizar com maior clareza no Gráfico 1 o crescimento dos resultados das vendas internas deflacionadas de materiais de construção segundo a ABRAMAT (2011). 
Gráfico 1 - Resultado das vendas internas deflacionadas de materiais de construção

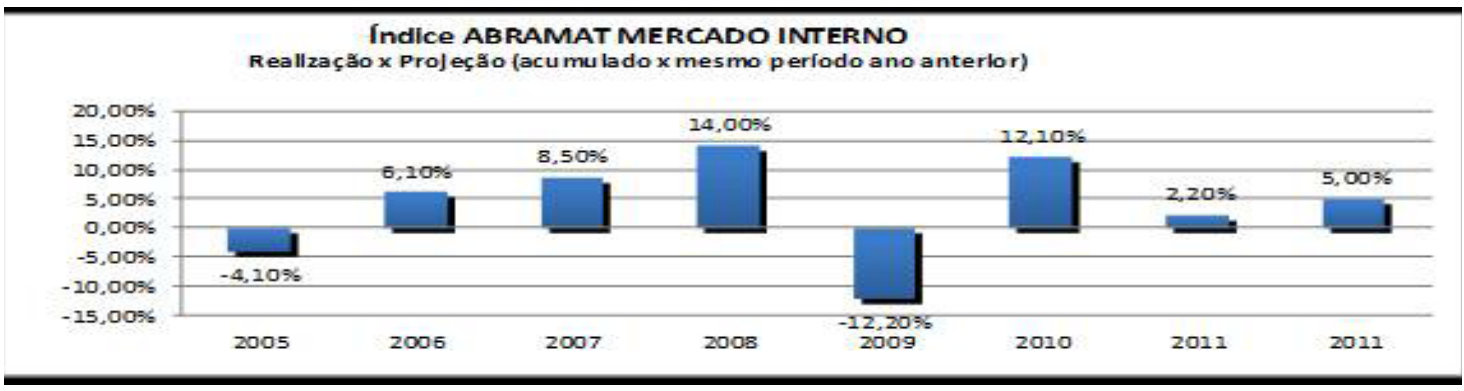

Fonte: ABRAMAT (2011).

Sendo a construção civil o segmento que consome a produção de revestimentos cerâmicos, a expectativa é que o mercado se mantenha aquecido. O setor no Brasil tem sua capacidade produtiva estimada para 2011 na ordem de 803 milhões de m² contra 754 milhões de m² em 2010 (Gráfico 2), segundo a Associação Nacional dos Fabricantes de Cerâmica para Revestimentos (ANFACER). Esse crescimento contínuo do setor já teve seu início a partir da década de 90, quando experimentou forte expansão, principalmente em decorrência da estabilidade econômica advinda do Plano Real e da substituição de outros revestimentos (carpetes, madeira, tecidos, vinil, mármore tinta, argamassa, concreto aparente, entre outros) por cerâmica. Essa substituição se deu devido às vantagens técnicas e estéticas da cerâmica: design, durabilidade, manutenção e higiene.

Figura 2 - Produção brasileira de revestimentos cerâmicos

\section{Produção Brasilelra de Revestimentos Cerâmicos} (millh бes $\mathrm{m}^{2}$ )

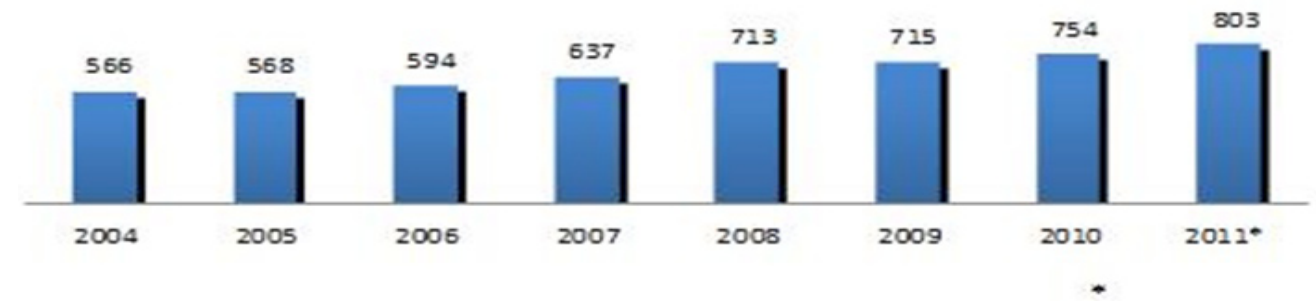

Fonte: ANFACER (2011).

Nota: em milhões de $\mathrm{m}^{2}$. * Estimativa.

\section{OS PRINCIPAIS COMPETIDORES NACIONAIS}

Além da competição no setor advinda da forte entrada de produtos cerâmicos importados, no país há a presença de fortes competidores como a Cecrisa e a Eliane. A Cecrisa S.A é uma companhia aberta que produz e comercializa produtos com as marcas Cecrisa e Portinari. Com sede na cidade de Criciúma - SC, foi constituída em junho de 1966. É hoje (2011) a maior empresa de revestimentos cerâmicos do país. Tem o maior faturamento entre as empresas do setor confirmando sua posição de liderança.

Há 45 anos no mercado, a Cecrisa tem como missão proporcionar estilo e bem-estar mediante soluções integradas para todos os ambientes. Seus principais valores são: responsabilidade social e ecológica, calor humano, comprometimento, austeridade, ética, criatividade e eficácia. Além de comercializar seus produtos para todo o território nacional, exporta para mais de 50 países em cinco continentes. Sua produção anual é de cerca de 37 milhões de metros quadrados de revestimentos entre porcelanatos, revestimentos de parede, pisos e peças especiais, atendendo pelos canais de varejo e engenharia. Considerado sua produção em relação ao total da indústria no Brasil, estimase que a empresa represente pouco mais de $4.6 \%$.

A Eliane Revestimentos Cerâmicos também foi fundada no início da década de 60 em Cocal do Sul - SC, onde fica a sede administrativa e quatro das 11 unidades fabris, incluindo uma unidade 
produtora de argamassas e rejuntes que é a Eliane Argamassas. A Eliane uma empresa brasileira dedicada à fabricação e à comercialização de revestimentos cerâmicos para os mercados interno e externo, com produção em 2011 de cerca de 32 milhões de metros quadrados. Nos seus mais de 50 anos de atuação, a Eliane tem experimentado concreto crescimento empresarial, adaptando-se rápida e eficazmente às constantes mudanças de um setor altamente competitivo. É uma empresa de expressão mundial em revestimentos com soluções completas, coordenadas e inovadoras. Pioneira no Brasil em diversos produtos e processos de fabricação, com destaque para o porcelanato técnico e o porcelanato de grandes formatos. Sua ampla gama de produtos inclui porcelanatos, revestimentos cerâmicos, complementos e argamassas para rejuntamento e assentamento. A estratégia de distribuição da Eliane se dá pelos canais revenda e engenharia. Estimada a participação da produção total da Eliane em 2011 e comparada ao total do setor no país, a empresa respondeu por cerca de $4 \%$ de share.

\section{A PORTOBELLO S.A.}

A empresa Portobello é uma marca internacional de revestimentos cerâmicos e uma das líderes desse segmento no Brasil. Ela foi constituída em 22 de dezembro de 1977 com uma visão clara de futuro, pautada pela inovação, pioneirismo e globalização. É uma empresa que representa liderança em qualidade, diferenciação, estilo, inovação e criação de tendências.

A Portobello é uma empresa de capital aberto desde 30 de abril de 2008, quando aderiu ao Novo Mercado da Bovespa, segmento de listagem que congrega empresas que, voluntariamente, se comprometerem a cumprir com as mais exigentes normas de Governança Corporativa, que vão além do que é exigido pela legislação societária brasileira. Por meio deste direcionamento, disponibiliza todos os seus dados econômicos publicamente e mantém uma gestão profissionalizada. A empresa reconhece a influência de suas ações sobre os interesses dos acionistas, colaboradores, franqueados, clientes, parceiros, fornecedores, comunidade, entre outros e, em função disto, busca o equilíbrio e a coerência de suas ações, visando ao benefício de todos.

Sediada na BR 101, Km 163, na cidade de Tijucas - SC, possui uma localização estratégica, visto estar próxima aos portos e às principais rotas rodoviárias nacionais e internacionais, e próximas ao centro geográfico onde estão seus principais mercados, entre eles São Paulo e Rio de Janeiro (Figura 1).

Em 2011 o parque fabril da companhia contava com dezesseis linhas de produção, instaladas em uma área total de mais de 500 mil metros quadrados, que geram anualmente uma produção de cerca de 23,5 milhões de metros quadrados, destinados ao mercado interno e também às exportações, as quais atingem 65 países da Europa, Ásia, América do Norte, Oceania, Oriente Médio e África, além da América Latina. Essa produção total posiciona a empresa como a terceira maior companhia nacional do setor, representando $2.9 \%$ da produção nacional estimada. 
Figura 1 - Representação gráfica da cobertura de mercado a partir de sua localização

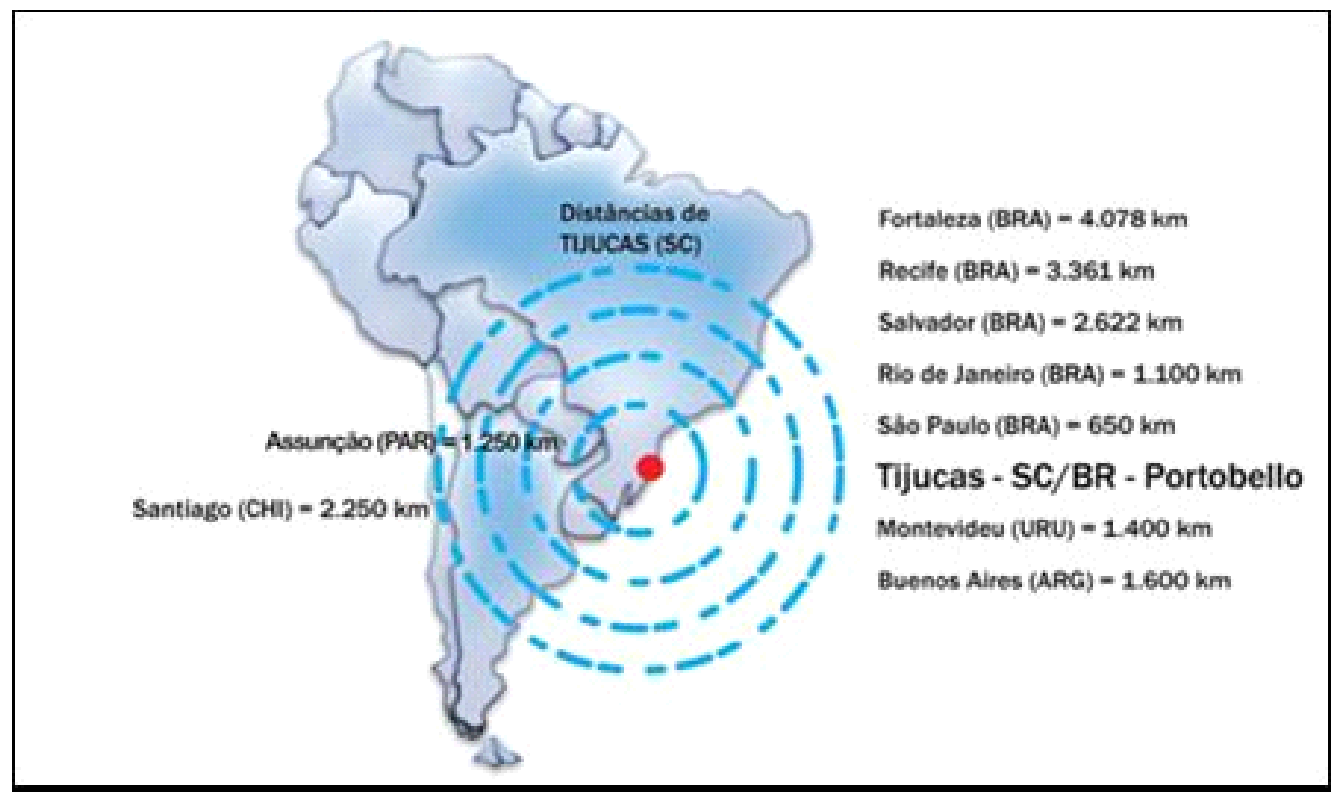

Fonte: Portobello (2011).

Considerado sua presença doméstica e internacional, a Portobello tem um modelo próprio de relacionamento com o mercado consumidor e a estratégia de distribuição da companhia está alicerçada em quatro canais distintos e com características específicas de portfólio de produtos, serviços e política comercial, que buscam competitividade e elos que fomentem a busca por excelência em toda cadeia produtiva. O Mercado Interno (MI) é atendido em três canais de distribuição:

Portobello Shop (PBS) - Franquias que atendem os clientes de varejo por meio das lojas franqueadas. As lojas são resultado da busca por tendências, novidades, revisão de conceito, criação de soluções e design inovadores.

Varejo Multimarca (REV) - Responsáveis pelo atendimento a revendedores de materiais de construção que vendem os produtos Portobello no varejo. Dentre tais revendedores, encontram-se os maiores home centers brasileiros e lojas especializadas em material de acabamento. Tipicamente, estes clientes mantêm estoques dos produtos de maior giro em seus depósitos e dependem do fornecedor para entrega dos produtos de menor giro. O perfil típico do consumidor final de revestimento cerâmico neste canal é pessoa física ou pessoa jurídica realizando obra de pequeno porte.

Engenharias (ENG) - Representadas por equipes especializadas que atendem empresas de construção civil, construtoras e incorporadoras imobiliárias. A distribuição para engenharias consiste nas vendas de soluções completas para revestimento cerâmico de grandes prédios residenciais e comerciais. Tal setor requer serviços e esforço de pré-venda que se iniciam até dois anos antes da efetivação da venda. Neste período são definidas, em conjunto com o cliente, as soluções que possam atender todos os requisitos da obra, sejam eles produtos de portfólio, peças especiais sob encomenda, sistema de transporte, armazenamento, plano de entrega, plano de financiamento, entre outros.

Já o Mercado Externo (ME) compreende as vendas realizadas para diversos países por meio de equipe própria e representantes independentes. As exportações em 2011 foram limitadas a mercados mais rentáveis e tiveram sua participação nas vendas totais reduzidas. Os resultados apurados de comercialização no ano de 2011 em m² são apresentados na Figura 2, conforme participação do canal no total da empresa. 
Figura 2 - Resultado contábil em $\mathrm{m}^{2}$ - Portobello Shop

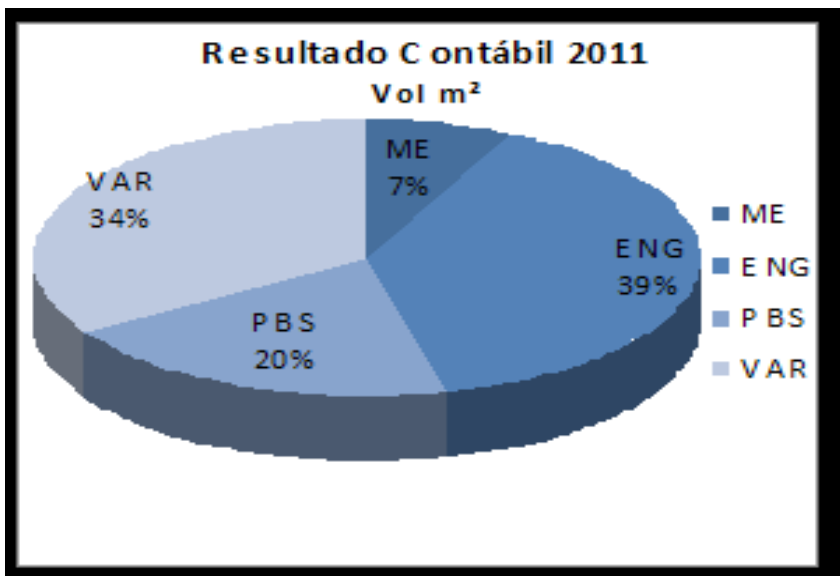

Fonte: Material interno PB Shop.

\section{DIRECIONAMENTO ESTRATÉGICO DA PORTOBELLO S.A}

A Portobello inova não apenas em seu mix de produtos, mas também em sua gestão. Está sempre buscando a transformação e a evolução em seus negócios. Seu planejamento estratégico atual foca toda gestão da cadeia de valor no qual está inserida. O desafio é simplificar e evoluir em sua operação, reduzindo o nível de controle manual dos processos, os retrabalhos existentes e garantir um fluxo de execução leve e ágil, de forma que as definições estratégicas sejam adotadas por todos os níveis.

A partir do diagnóstico realizado com a participação de todas as áreas, as iniciativas foram estruturadas em três ondas de inovação: Simplificação, Estruturação e Diferenciação. A fase de simplificação amplia a eficiência operacional, tornando os processos mais ágeis e confiáveis; A fase de estruturação programa e implementa melhorias nos processos de planejamento de curto e médio prazo, criando fóruns de alinhamento entre Comercial, Industrial e Logística, com ferramentas de Planejamento de Vendas, Avaliação de Capacidades, Acompanhamento da Carteira, gerando maior Confiabilidade no atendimento aos clientes; A fase de diferenciação, dividida em duas etapas, garante um novo patamar de relação com o cliente e com os canais de venda, ampliando a rentabilidade e o nível de serviço praticado.

Em entrevista, o Presidente da Portobello, Cesar Gomes Junior, relata que:

A Empresa ganha em modernização dos processos e com isso melhores resultados; e as pessoas ganham à medida que realizam seu trabalho de forma mais ágil e com melhores formas para atingir suas metas. A soma do esforço de cada um é resultado de toda a empresa. O caminho que vamos seguir já começou a ser trilhado. O primeiro passo, que foi a fase de diagnóstico, já foi finalizado e em um ritmo muito bom. A empresa até 2013 dará foco e continuidade nesse desafio de superação de metas, mantendo a busca da alta performance, e isso só será possível através de um trabalho de equipe, com todas as áreas atuando na mesma direção. (PBNEWS, 2011, s.p.).

Nenhuma empresa pode ser a melhor em todos os critérios dentro da cadeia de valor, por isso corporativamente a Portobello optou por uma estratégia de diferenciação, direcionando seus esforços para ser reconhecida como a mais confiável do mercado de revestimentos cerâmicos. Isso significa ter maior credibilidade aos olhos dos consumidores, com posicionamento de proximidade ao cliente por meio da rapidez e da confiabilidade. Porém, apesar desse foco, sem deixar de se preocupar com a gestão de produtos e na eficiência operacional. Na Figura 3, apresenta-se o esquema que permeia este direcionamento por meio dos trade-offs estratégicos. 
Figura 3 - Os Trade-offs ou Escolhas Estratégicas

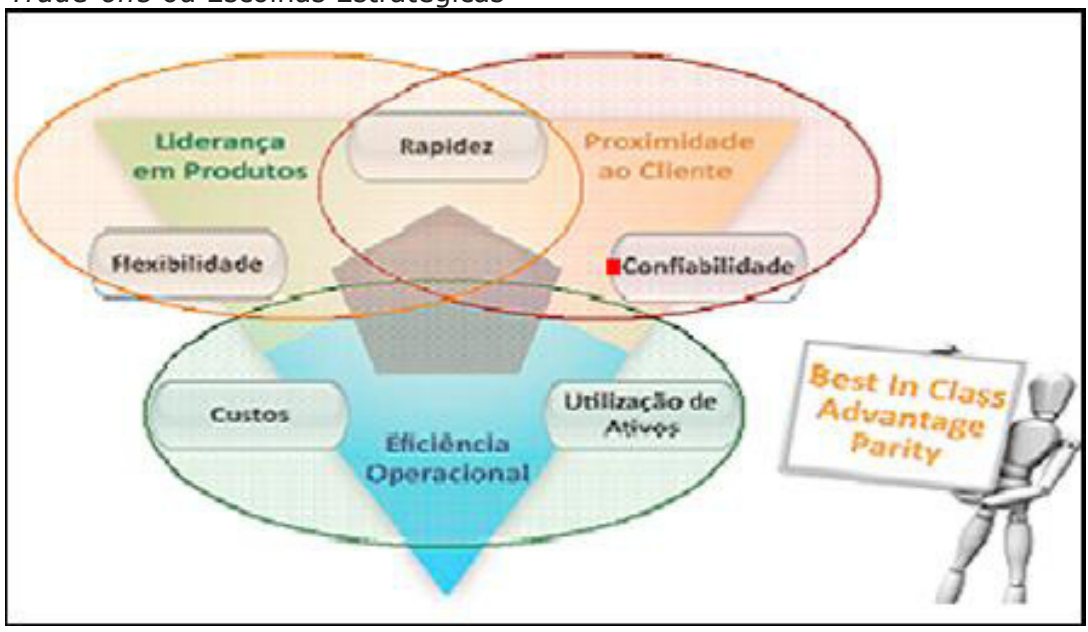

Fonte: Documento interno da empresa.

\section{A PORTOBELLO SHOP}

Implantada em 1998, a Portobello Shop, empresa subsidiária da Portobello S.A, é a única rede de franquias especializada em revestimentos cerâmicos do Brasil. Criadas para aproximar a indústria do cliente final, as lojas corresponderam, no ano de 2011 , por $20 \%$ das vendas da companhia. Conta com mais de 100 lojas instaladas em todo o Brasil operadas por mais de 60 franqueados, que atuam em unidades de diferentes formatos, classificados em Compacto, Tradicional e Empório. No Quadro 1 são apresentadas características de cada modelo.

Quadro 1: Tipos e características dos diversos tipos de Portobello Shop

\begin{tabular}{|l|l|l|}
\hline \multirow{4}{*}{ Formato de loja "Compacto" } & Área total & $100 \mathrm{~m}^{2}$ \\
\cline { 2 - 3 } & Área de exposição & $90 \mathrm{~m}^{2}$ \\
\cline { 2 - 3 } & No de funcionários & $03+\mathrm{franqueado}$ \\
\cline { 2 - 3 } & Investimento estimado & $255.000,00$ \\
\hline \multirow{4}{*}{ Formato de loja "Tradicional" } & Área total & $230 \mathrm{~m}^{2}$ \\
\cline { 2 - 3 } & Área de exposição & $210 \mathrm{~m}^{2}$ \\
\cline { 2 - 3 } & No de funcionários & $10+\mathrm{franqueado}^{-}$ \\
\cline { 2 - 3 } & Investimento estimado & $608.000,00$ \\
\hline \multirow{3}{*}{ Formato de loja "Empório" } & Área total & $200 \mathrm{~m}^{2}$ \\
\cline { 2 - 3 } & Área de exposição & $190 \mathrm{~m}^{2}$ \\
\cline { 2 - 3 } & No de Funcionários & $08+\mathrm{franqueado}^{2}$ \\
\cline { 2 - 3 } & Investimento Estimado & $448.000,00$ \\
\hline
\end{tabular}

Fonte: Produzido pelo autor a partir de dados da empresa.

Para abertura de uma nova franquia da Portobello Shop, o grupo Portobello realiza análises de mercado que definem previamente o formato de loja mais adequado para a cidade, oferece todo apoio para franqueada com uma consistente estratégia de comunicação e marketing, treinamentos, e ainda tem constituído uma equipe de consultores de campo, responsáveis pela supervisão e pelo desempenho das unidades. Conta também com o Conselho de Franqueados que realizam reuniões periódicas, buscando tomar decisões importantes para o desenvolvimento da rede. 


\section{O PROCESSO LOGÍSTICO DA PORTOBELLO SHOP}

A operação logística de atendimento à Portobello Shop é um caso único na operação da Cerâmica Portobello e um desafio para os seus gestores. Este canal não detém o maior volume em metro quadrado ( $20 \%$ do total), mas detém o maior número de acessos em diferentes docas para separação, aumentando assim o tempo de execução de fechamento de uma carga, aumento de mão de obra, maior volume de embalagens, devido à unitização customizada da carga. O número de acessos por pedidos nos diferentes canais é apresentado no Anexo 1.

O entendimento desse processo torna-se mais evidente a partir do fluxograma das operações logísticas da Portobello Shop (Figura 4) para atendimento dos pedidos. Este se inicia na entrada do pedido no sistema e finaliza com a entrega do produto ao cliente.

Figura 4 - Fluxo de atendimento ao pedido - separação e faturamento

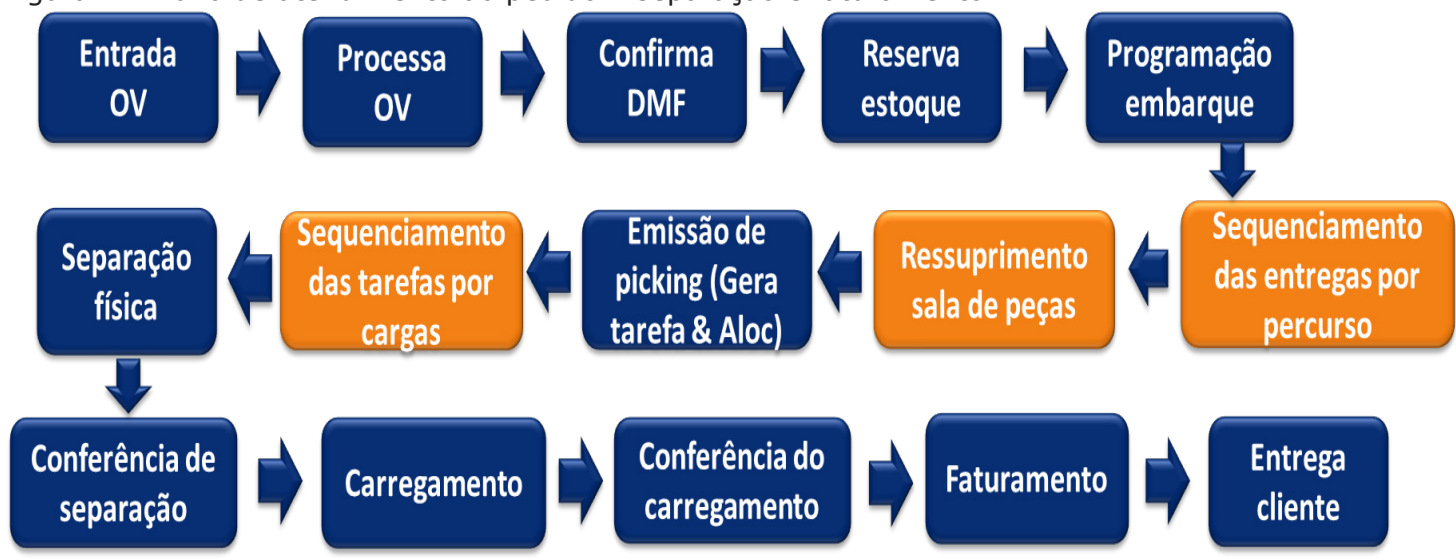

Fonte: Material interno PB Shop.

O produto do mix de oferta que merece maior atenção dos gestores de logística é o Porcelanato. Campeão de vendas no canal PB Shop, o mesmo é um tipo de revestimento cerâmico fabricado com tecnologia avançada. Diferencia-se dos demais revestimentos em função do seu processo de queima em alta temperatura, das matérias-primas nobres que compõem a sua massa e também da absorção de água que é baixíssima, sendo $<0,1 \%$ para os porcelanatos técnicos e $<0,5 \%$ para os porcelanatos esmaltados. O portfólio de produtos comercializados pela Portobello apresenta uma grande diversidade de formatos, com dimensões de até 1,20 x 1,20 e espessuras que variam de $6 \mathrm{~mm}$ a $3 \mathrm{~mm}$. Estes produtos são fabricados em peças individuais, embalados em caixas e unitizados em pallets.

Dependendo do formato do produto, suas características de resistência variam, determinando a capacidade de sua embalagem. Estas características são estudadas junto com a criação de cada produto, para que quando o mesmo esteja pronto, seja possível definir quantas peças podem ser agrupadas por caixa, quantas camadas de caixas pode ser sobreposta em cada pallets e ainda a capacidade máxima de empilhamento dos pallets para estocagem ou transporte. Além destas variáveis específicas dos produtos, os pallets de cada formato passam por um estudo de montagem e amarração, para que sua estrutura resista ao manuseio interno e transporte, com testes específicos de simulação das forças físicas as quais serão submetidos. Antes de sair da fábrica para armazenamento, todos os produtos são embalados em pallets de forma automatizada na própria fábrica. Depois de montados, os pallets são embalados em um plástico especial que protege as caixas dos produtos de intempéries, umidade e raios UVS/UVB, para que possam ser armazenados em áreas abertas. Depois de embalados, pallets são identificados com uma etiqueta de código de barras, contendo o código único de identificação dos pallets, o código e a descrição do produto, seu lote, data de fabricação e sua tonalidade e calibre.

As características do revestimento cerâmico também implicam restrições diretas no seu manuseio e transporte, devido a sua fragilidade e peso, o que dificulta e exige dos profissionais estratégicos 
e operacionais maior atenção. Os pallets de revestimento cerâmico da Portobello pesam em média de 1 a 2,5 toneladas, dependendo do formato do produto, e o transporte dos mesmos das áreas de produção às áreas de armazenamento é feito por intermédio de caminhões. As empilhadeiras carregam os pallets produzidos na saída das fábricas para os caminhões, lendo suas respectivas etiquetas de código de barras, para apontar a saída da produção. Estes pallets são então levados para as áreas de descarga, para que sejam descarregados e armazenados.

Um sistema de WMS (Warehouse Management System) é utilizado pelas empilhadeiras, o qual indica o endereço mais apropriado de armazenamentos dos produtos, no momento em que os operadores realizam a leitura das etiquetas dos pallets. O endereço sugerido pelo sistema WMS se baseia em regras definidas pela equipe de logística da Portobello, considerando aspectos do produto como: curva $A B C$, fragilidade, tamanho, capacidade de blocagem, valor financeiro e também atributos das áreas de armazenamento, como: distância das áreas de carga, tipo de pavimentação, tamanho, capacidade e limite de peso (um único endereço pode comportar 15 pallets de 2 toneladas cada, o que exige uma resistência mínima do solo para que o mesmo não ceda). 0 operador então leva os pallets até o endereço, confirmando por rádio frequência o armazenamento dos pallets no endereço indicado pelo sistema. A partir deste momento a respectiva quantidade do produto entra como saldo para venda.

Conforme relatado pela coordenadora de varejo e franquias da Portobello Shop, a empresa tem investido em tecnologia e processos. O objetivo é tornar a empresa mais preparada para os desafios do mercado e dentro de um novo contexto de infraestrutura logística. Os investimentos no curto prazo devem permanecer com foco no planejamento da malha logística, buscando a otimização e o ganho de escala.

Depois de o pedido de venda confirmado, as transportadoras acessam o sistema da Portobello para planejarem a distribuição e a entrega dos produtos comprados. As equipes das transportadoras, com base nos seus próprios critérios de logística, montam os percursos e as distribuições das demandas de entregas, de acordo com a quantidade e o formato dos produtos, da distância da entrega e da disponibilidade e da capacidade dos caminhões que serão alocados. A equipe da Portobello confirma os percursos e as distribuições das transportadoras, agenda a data para o carregamento e inicia o processo de separação e preparação das cargas.

A agenda infelizmente nem sempre é seguida e, muitas vezes, o cliente acaba entrando em contado com a própria transportadora, bagunçando toda a estrutura logística. O coordenador na área logística menciona que: "No que tange a operação interna de separação e carregamento dos pedidos, o fato de termos apenas com 24 horas de antecedência a informação do que será carregado e a falta de fluxo em alguns dias são uns dos maiores entraves para o não atingimento do OTIF". Exemplo disso é a demanda irregular. Mesmo dentro da semana há "um acúmulo nas quintas e sextasfeiras e uma ociosidade de domingo a terça-feira". Esta situação se acentua ainda mais conforme o período do mês. "No momento a falta de automação limita as ferramentas de gestão do armazém principalmente o controle da produtividade dos colaboradores e a qualidade dos serviços".

As cargas das entregas podem ser fechadas ou fracionadas. As cargas fechadas consistem em pallets fechados e as cargas abertas em combinações de pallets, caixas e até mesmo peças individuais, que atendem às compras dos clientes nas lojas da franquia PB Shop (pallets solução). O maior desafio da logística é o manusear as caixas e as peças individualmente, devido a sua fragilidade. $\mathrm{O}$ risco não se aplica somente à quebra, mas também aos danos leves, como lascados nas pontas e arranhões na superfície, que já descaracterizam o produto para comercialização, comprometendo a entrega e, consequentemente, o cumprimento do On Time In Full (OTIF) medido pela empresa. Depois de separadas, as cargas ficam aguardando a chegada dos caminhões para que sejam carregadas e conferidas. Os caminhões programados, quando chegam para buscar suas respectivas cargas, acusam que estão disponíveis na portaria da empresa. Quando a expedição confirma que a carga está pronta, o caminhão é pesado vazio na portaria, estaciona em uma doca de carregamento e aguarda que as empilhadeiras transfiram a carga separada para a carroceria. Depois de carregado, o caminhão é conferido, agora com a carga, para que seu peso seja verificado com o valor indicado na nota fiscal. Confirmado, o mesmo é liberado para entrega.

A partir disto, o caminhão segue ao seu destino, que pode ser um armazém de transit point, para um centro de distribuição ou ainda diretamente ao consumidor final ou loja. No Quadro 2 
seguem as descrições das operações de transit point e Centros de Distribuição. Ao realizar a entrega, a transportadora envia um relatório (Anexo 2) para a empresa, para que seja feito o controle da entrega e, consequentemente, uma avaliação do indicador de OTIF. Porém essa é possivelmente a maior dificuldade, pois esse procedimento conduz a alguns Gaps.

Quadro 2: Características dos destinos TP e CD para algumas cargas da Portobello Shop

\begin{tabular}{|l|l|}
\hline \multirow{4}{*}{ Transit Point (TP) } & Transbordo de carga de um veículo grande para outros menores \\
\cline { 2 - 2 } & Pallet não pode ser aberto, apenas se for embalagem vermelha, \\
& que significa mais de uma entrega no mesmo pallet. \\
\cline { 2 - 2 } & Não é cobrada estadia do produto no prazo de 10 dias \\
\hline \multirow{2}{*}{ Centro de Distribuição (CD) } & A loja PB Shop deve enviar a nota antecipadamente ao CD \\
\cline { 2 - 2 } & Os pallets são abertos e fracionados conforme Notas Fiscais \\
\cline { 2 - 2 } & Podem ocorrer entregas parciais ao cliente. \\
\hline Fonte: Produzido pelo autor a partir de dados da empresa.
\end{tabular}

Uma das maiores dificuldades com que se deparam os responsáveis pela logística da empresa é justamente o controle de envios, pois somente há como saber de certeza quando a mercadoria passa na balança, ou seja, quando a nota fiscal é emitida e o caminhão sai da empresa. Apesar de haver um relatório para este controle, dificilmente o caminhoneiro preenche e a informação chega aos controles da empresa.

Isso pode ser retratado conforme mencionado pelo Coordenador na área de Informática voltada à logística: "como o cliente paga o frete $\left(\mathrm{FOB}^{1}\right)$, não temos total controle sobre a transportadora. Neste caso, programamos embarque para uma data, mas o cliente desmarca com a transportadora, e perdemos tempo separando uma carga que não vai embarcar". Quando ocorrem cargas separadas que não embarcam, essas ocupam faixas de separação que são muito concorridas, além de consumir tempo que poderia ter sido usado para separação de outras cargas, que muitas vezes são de caminhões esperando no pátio. Outro ponto destacado é o "não recebimento dos controles de entrega que a transportadora deveria fazer para empresa, aumentando a dificuldade para o controle do OTIF, o que temos hoje serve apenas para medir a eficiência do processo, e não temos como medir a chegada da entrega no cliente".

Outras áreas do negócio também observam essa dificuldade. De acordo com a Coordenadora da área de Telemarketing "um dos fatores para o não atingimento do OTIF é que não temos sistema integrado com as transportadoras, o frete é FOB, então dependemos da informação da transportadora confirmando a entrega em tempo real e isso quase sempre não acontece". Outro fator importante e "a Inconsistência entre produção e carteira de pedidos, gerando atrasos nas datas acordadas de entrega. Não existe hoje uma data de desejo confiável, muitas vezes o vendedor lança uma data de entrega diferente da expectativa do cliente".

Com o objetivo de estabelecer um ponto único de contato pós-faturamento, a Portobello Shop, por meio de seus gestores, criou uma estrutura especial denominada "Linha Direta Logística" para que seja direcionado qualquer problema após a confirmação do faturamento. Uma equipe interna acompanha os chamados e os respectivos atendimentos para melhoria contínua. Este grupo está capacitado a interagir com os elos da cadeia na busca de uma resposta rápida e solução em tempo hábil, minimizando assim problemas eventuais ao longo do fluxo de distribuição. Caso o atendimento não esteja indo em direção a uma solução ideal para a loja, a mesma poderá escalar o problema a um grupo de gestão, enviando uma mensagem por e-mail.

1 FOB: Frete FOB - Free on board: A sigla FOB em português pode ser traduzida por "Livre a bordo". Neste tipo de frete, o comprador assume todos os riscos e custos com o transporte da mercadoria, assim que ela é colocada a bordo do navio. Por conta e risco do fornecedor fica a obrigação de colocar a mercadoria a bordo, no porto de embarque designado pelo importador. 


\section{GESTÃO POR INDICADORES}

Conforme objetivos e direcionamento estratégico da empresa, seus gestores na área de logística tem o propósito de medir cada etapa do elo a fim de obter melhoria contínua e cumprir as metas de prazo de entrega. Esse acompanhamento de indicadores ocorre desde a entrada do pedido colocado pela loja ou pela equipe de apoio (administração de vendas e telemarketing), a liberação de filtros de retenção, como desconto, prazo de pagamento, financeiro, entre outros. Inclui também o acompanhamento na expedição em todas as etapas desde a separação até o embarque, o acompanhamento junto às transportadoras e operadores logísticos até a entrega no cliente, processo que não deverá passar de 12 dias. A redução dos tempos envolvidos nos processos descritos é uma importante força propulsora na busca pela geração de valor nos processos dentro e fora da empresa. Além de grande desafio é de suma importância para aumentar a flexibilidade em relação aos seus concorrentes e também aumentar a confiabilidade perante seus clientes.

Diante deste desafio e escopo organizacional, posicione-se como gestor da área de logística da empresa e avalie as condições atuais e potenciais para ampliar o desempenho logístico no canal PB Shop.

NOTAS DE ENSINO

\section{OBJETIVOS EDUCACIONAIS}

Os principais pontos do case da Portobello Shop estão relacionados às dificuldades e aos desafios para atingir a excelência em atendimento ao cliente para ser tornar mais confiável no desempenho logístico junto ao mercado, apoiada pelas operações logísticas de alto nível e pela implantação do indicador de desempenho OTIF.

Nesse sentido o caso poderá ser utilizado por acadêmicos de cursos de graduação e pós-graduação nas áreas de gestão, principalmente em disciplinas da área de logística e supply chain. Nestas, poderão discutir sobre estratégias aplicadas, desafios de mercado, exigência dos concorrentes, gargalos para implantação de novos indicadores, posicionamento estratégico das empresas e competitividade do mercado. Essa natureza multidisciplinar permite que o caso seja ainda aplicado a outras disciplinas, desde que criadas novas questões direcionadas de forma específica aos temas de estudo de interesse do professor.

\section{FONTES DE DADOS}

O caso foi elaborado a partir de dados primários e secundários. Os dados secundários foram retirados de documentos institucionais da empresa, sites de empresas do segmento cerâmico, de organizações e associações do setor, bem como reportagens publicadas em veículos de comunicação utilizadas para completar algumas informações. Já os dados primários foram coletos a partir de colaboradores da empresa de áreas como: tecnologia de informações, coordenação de vendas, expedição e telemarketing por meio de entrevistas não estruturadas.

\section{QUESTÕES PARA DISCUSSÃO}

1 - Como gestor da área de logística da empresa, qual a relevância pode ser atribuída à implantação e ao alcance de um alto nível de desempenho do índice de OTIF para apoiar o posicionamento competitivo da Portobello e, consequentemente, da Portobello Shop?

2 - Quais desafios e oportunidades a implantação da OTIF traria para a operação logística da Portobello Shop?

3 - Conforme Bowersox e Closs (2001), atender aos pedidos sempre de maneira perfeita não 
é uma tarefa fácil, porém possível na medida em que se busca um aperfeiçoamento contínuo das atividades logísticas chaves: projeto de rede, informação, transporte, estoque e, finalmente, atividades ligadas à armazenagem, ao manuseio de materiais e às embalagens. Diante disto, relacione o que a operação logística da Portobello Shop vem desenvolvendo em cada uma dessas atividades e como isso vem influenciando positivamente ou negativamente na implantação e na conquista de um alto nível de OTIF.

\section{ANÁLISE DO CASO E CONEXÃO COM A LITERATURA}

Padrão de resposta Questão 1 - Com a implantação do OTIF, a empresa Portobello/Portobello Shop conseguiria melhorar suas práticas no que tange à competência logística, tendo assim maior visibilidade de todos os processos do ciclo do pedido, pois esta é uma forma de monitorar e ajustar as deficiências, aumentando o desempenho de atendimento do pedido perfeito. $O$ indicador OTIF controla as entregas realizadas dentro do prazo, atendendo as quantidades e as especificações dos produtos do pedido do cliente. Pode se dizer que a entrega do pedido que atenda as necessidades e a promessa de serviço ao cliente assume grande relevância, pois sustenta o posicionamento de confiabilidade que a empresa Portobello/Portobello Shop deseja firmar, além de estabelecer na visão de seus clientes a confiança e influenciando na fidelidade.

Reforçando essa relação, Ballou (2002) afirma que um produto ou serviço, se não estiver no tempo e no lugar certo para que o cliente possa consumi-lo, terá pouco valor ao cliente. $O$ desafio para a organização que pretende ser líder em serviço ao cliente é conhecer as exigências dos diferentes segmentos em que atua e reestruturar seus processos de logística em direção aos cumprimentos dessas exigências. $O$ autor ainda salienta que o problema a ser enfrentado pela logística é diminuir o hiato entre a produção e a demanda, de modo que os consumidores tenham bens e serviços quando e onde quiserem e na condição física que desejar.

A Portobello/Portobello Shop, com sua visão inovadora, busca sair na frente de seus competidores, tendo em vista que fabricantes como Eliane e Cecrisa, além dos players internacionais, não usam a ferramenta OTIF como um diferencial competitivo. A condução eficaz da logística e do gerenciamento da cadeia de suprimentos pode fornecer importante fonte de vantagem competitiva em relação aos concorrentes. Desta forma, a função logística, como uma atividade primária na cadeia de valor, configura uma importante fonte na busca por oportunidades de diferenciação e custos, portanto, com alto nível de influência para criação de vantagem competitiva sustentável no mercado (PORTER, 1989).

Diante da situação, observou-se a importância dessa boa prática como um grande fator de diferenciação e essencial para a sobrevivência da empresa diante de um ambiente competitivo.

Padrão de resposta Questão 2 - A Portobello/Portobello Shop é conhecida não só pela qualidade de seus produtos, mas também por ser uma empresa inovadora, e diante das novas estratégias surge a grande oportunidade de se tornar a empresa mais confiável do mercado cerâmico, por meio da implantação do OTIF. Por mais que a definição de OTIF seja simples, a sua implantação é muito desafiadora, contudo seus resultados quando alcançados são significativos na percepção da qualidade para os clientes.

Bowersox e Closs (2001) descrevem que, para obter um desempenho logístico que atenda continuamente às expectativas dos clientes, é essencial que a empresa tenha um compromisso com o aperfeiçoamento contínuo. Esta informação vem ao encontro dos maiores desafios da empresa, que são todos os alinhamentos dos processos internos, como produção, vendas e expedição, e a busca de otimização para ganho de escala e eficiência operacional, facilitando o trabalho de todos envolvidos e zelando a marca Portobello/ Portobello Shop.

À luz de várias entrevistas realizadas com funcionários da empresa, destacam-se alguns entraves para a implantação do OTIF, como a falta de um sistema integrado entre a empresa e as transportadoras. O frete é FOB e a Portobello depende de informações vindas das transportadoras, confirmando a entrega em tempo real, e isso nem sempre acontece. Desta forma, tem-se como grande barreira a conscientização dos próprios caminhoneiros. 
Outro desafio é a inconsistência entre a produção e a carteira de clientes, pois muitas vezes o vendedor lança um pedido e o cliente depois solicita alteração na data de entrega para maior ou para menor, causando distorções nas projeções de produção. Essas alterações de datas muitas vezes são solicitadas pelo cliente e a carga já está até em processo de separação, aumentando ainda mais os transtornos, já que envolvem o processo de expedição.

Contudo, conforme Kobayashi (2000) menciona, a logística é a atividade que pode criar a diferença em relação aos concorrentes e oferecer uma vantagem competitiva. É na logística, portanto, que devem ser efetuados os melhoramentos e as inovações que servem para aumentar a própria competitividade. Enquanto se estabelece o esforço para melhorar a qualidade, diminuir custos, reduzir prazos, aumentar a segurança, deve-se procurar, também, outros caminhos para enfrentar os desafios e incrementar o valor da própria empresa. Neste sentido, destacam-se como oportunidades os seguintes aspectos:

Sugere-se então que as ações com a implantação do OTIF não sejam somente reativas, possibilitando maior pró-atividades na atuação de algumas necessidades no ciclo do pedido, como rapidez e agilidade, aumentando assim a eficiência no atendimento do pedido, a confiabilidade e a fidelização do cliente.

Padrão de resposta Questão 3 - Buscando uma maior competência de todas as operações logísticas chaves, a Portobello/Portobello Shop tem o objetivo de acompanhar cada etapa do atendimento do pedido para, com isso, desenvolver ações que reduzam os prazos de entrega, os custos, os erros, maximizando a possibilidade da entrega perfeita.

Assim como Michelle Nunes relata, a empresa está cada vez mais preparada para os desafios do mercado, mesmo dentro de uma nova infraestrutura logística.

No que compete ao projeto de rede, destaca-se o auxílio nas operações de transbordo e transit point estabelecidas em lugares geograficamente estratégicos e que têm ajudado na parte de fracionamento de separação de cargas, foco do modelo PBShop. Conforme Ballou (2002), o projeto de rede logístico tem como propósito determinar a quantidade e a localização de todos os tipos de instalações necessárias para a execução do processo logístico. A determinação do tipo de estoque e de volume a ser armazenado em cada instalação, assim como vincular os pedidos de clientes aos locais de onde devem ser expedidos, torna-se determinante para o sucesso da operação. Rocha (2003) descreve que essas escolhas são consideradas chaves para prover o nível de serviço necessário para gerar vendas e controlar custos.

Quanto às informações, Ballou (2002) esclarece que os sistemas de informação representam uma integração de dados, dando suporte ao equipamento, aos funcionários e aos métodos de resoluções de problemas que dão auxílio ao operador logístico no planejamento das operações. E esse talvez seja o grande gargalo da operação PBShop em direção ao alcance de índices de OTIF altos. As informações geradas ainda não são confiáveis, não por parte de sistema, mas sim porque há muitas divergências, e fatores não controláveis, como as alterações nas datas de desejo do cliente, assim como a própria a dificuldade de incluir informações a partir das operações das empresas transportadoras.

Isso também está relacionado à atividade de transporte. O fato de a Portobello trabalhar com o frete FOB - inclusive na Portobello Shop - torna o fator de decisão da empresa sobre as transportadoras pouco influente, pois o cliente é quem paga o frete, dificultando assim a exatidão na informação de entrega ao consumidor final, e da própria gestão do tempo de entrega. Nestes casos, aparentemente, parece que as responsabilidades da empresa se encerram na portaria da mesma.

As características do revestimento cerâmico não ajudam muito no quesito OTIF, pois implicam restrições diretas no seu manuseio e transporte, devido a sua fragilidade e peso. No caso específico da Portobello Shop, cujas cargas são muito fracionadas, acabam implicando também no tempo de processo de separação. Segundo Ballou (2003), é um dos itens de maior destaque na distribuição física, pois influencia diretamente na segurança dos produtos a serem movimentados, o que é uma grande fonte de riscos e custos para a organização.

Relativo às atividades de gestão de estoque, os mesmos são monitorados por um sistema de WMS, que indica alguns aspectos dos produtos, como: tamanho, fragilidade, distância da área de carga, capacidade de blocagem, etc. Para Ballou (1993), é necessário desenvolver procedimentos de 
controle que definam a frequência que os níveis de estoque devem ser comprados com o parâmetro de ressuprimento, para saber quando e quanto pedir. Este controle é parte vital do composto logístico, pois pode absorver $25 \%$ a $40 \%$ dos custos totais do capital da empresa.

Referente às informações expostas, prevê-se que muitos serão os impactos diante da dimensão das mudanças que envolvem todo o processo para nova estruturação das operações de logística e distribuição que a empresa almeja.

\section{REFERÊNCIAS}

ASSOCIAÇÃO BRASILEIRA DA INDÚSTRIA DE MATERIAIS DE CONSTRUÇÃO - ABRAMAT. Disponível em: <http://www.abramat.org.br>. Acesso em: 28 nov. 2011.

ASSOCIAÇÃO NACIONAL DOS FABRICANTES DE CERÂMICA PARA REVESTIMENTO - ANFACER. Disponível em: <http://www.anfacer.com.br>. Acesso em: 23 nov. 2011.

BALLOU, Ronald H. Logística empresarial: transportes, administração de materiais e distribuição física. São Paulo: Atlas, 1993.

Gerenciamento da cadeia de suprimentos. 4. ed. São Paulo: Bookman, 2002.

BOWERSOX, D. J.; CLOSS, David J. Logística empresarial: o processo de integração da cadeia de suprimentos. São Paulo: Atlas, 2001.

BRASIL. Banco Central do Brasil. Indicadores econômicos consolidados: Disponível em: <http:// www.bcb.gov.br/?indeco>. Acesso em: 15 abr. 2012.

INSTITUTO BRASILEIRO DE GEOGRAFIA E ESTATÍSTICA. Disponível em: <http://www.ibge.gov.br>. Acesso em: 21 nov. 2011.

KOBAYASHI, Shun'ichi. Renovação da logística: como definir estratégias de distribuição física global. São Paulo: Atlas, 2000.

PORTER, Michael E. Vantagem competitiva: criando e sustentando um desempenho superior. Rio de Janeiro: Campus, 1989.

ROCHA, Paulo César Alves. Logística \& aduana. 2. ed. São Paulo: Aduaneiras, 2003.

\section{BIBLIOGRAFIA RECOMENDADA}

ARAUJO, Ribeiro. Robustecimento da gestão logística através da implantação do indicador de desempenho OTIF. $6^{\circ}$ Congresso Anual da ABM. Disponível em: <http://www.primvs.com.br/arquivos/ APR_CongressoABM_2008_OTIF_7822.pdf>. Acesso em: 30 abr. 2012.

BALLOU, Ronald H. Gerenciamento da cadeia de suprimentos/logística empresarial. Porto Alegre: Bookman, 2006.

BOWERSOX, D. J.; CLOSS, David J.; COOPER, M. Bixby. Gestão logística de cadeias de suprimentos. Porto Alegre: Bookman, 2006.

COUNCIL OF SUPPPLY CHAIN MANAGEMENT PROFESSIONALS - CSCMP. Disponível em: <http://cscmp. org >. Acesso em: 28 nov. 2011. 
ANEXOS

Anexo 1: O número de acessos por pedidos nos diferentes canais

\begin{tabular}{|c|c|c|c|c|c|c|c|}
\hline Indicador & Qualificador & $20 / 01 / 2011$ & $20 / 2 \pi 011$ & $20 / 32011$ & $20 / 4 / 2011$ & $20 / 5 / 2011$ & $20 / 5 / 2011$ \\
\hline VOLUME SEPARADO POR M2 & ENGENHAFIA & 480.973 & 495.783 & 558.517 & 544390 & 563.934 & 611.419 \\
\hline VOLLME SEPARADO POR M9 & PQ SHOP & 412.995 & 459.963 & 467.953 & 406.951 & 460.869 & 455.856 \\
\hline OTDE ACESSOS DE SEPARACAO POR CAILAL & EIIGEIHAAPIA & 12.003 & 13.994 & 13.733 & 13.146 & 12.595 & 17.342 \\
\hline OTDE ACESSOS DE SEPARACAO POR CAILAL & EXPORTAÇÄO & 3.708 & 3.658 & 2.543 & 2.978 & 4.014 & 3.063 \\
\hline OTDE ACESSOS DE SEPARACAO POR CAILAL & PBSHOP & 38.094 & 38.433 & 32.080 & 30.543 & 36.379 & 31.829 \\
\hline OTDE ACESSOS DE SEPARACAO POR CAILAL & REVEIIDA & 14.527 & 13.828 & 13.286 & 10.952 & 12.698 & 13.329 \\
\hline VOLUME SEPARADO POR M4 & EXPORTAÇÃO & 220.536 & 219.446 & 148.601 & 196.870 & 157.168 & 98.644 \\
\hline VOLUME SEPARADO POR M9 & PQ SHOP & 511980 & 505.124 & 498.689 & 433.998 & 412.787 & 324,891 \\
\hline VOLUME SEPARADO POR M11 & REVENDA & 482.846 & 554.891 & 690.990 & 709.769 & 704.521 & 697.507 \\
\hline OTDE ACESSOS DE SEPARACAO POR CAILAL & EIIGEIHAPIA & 20.571 & 13.948 & 12.293 & 14.322 & 21.308 & 14.776 \\
\hline OTDE ACESSOS DE SEPARACAO POR CAILAL & EXPORTAÇÄO & 4.508 & 4.031 & 3.289 & 4.220 & 4.221 & 4.072 \\
\hline OTDE ACESSOS DE SEPARACAO POR CAILAL & PBSHOP & 36.044 & 38.986 & 34.850 & 37.523 & 38.449 & 35.921 \\
\hline
\end{tabular}

Anexo 2: Chek-list-Entrega

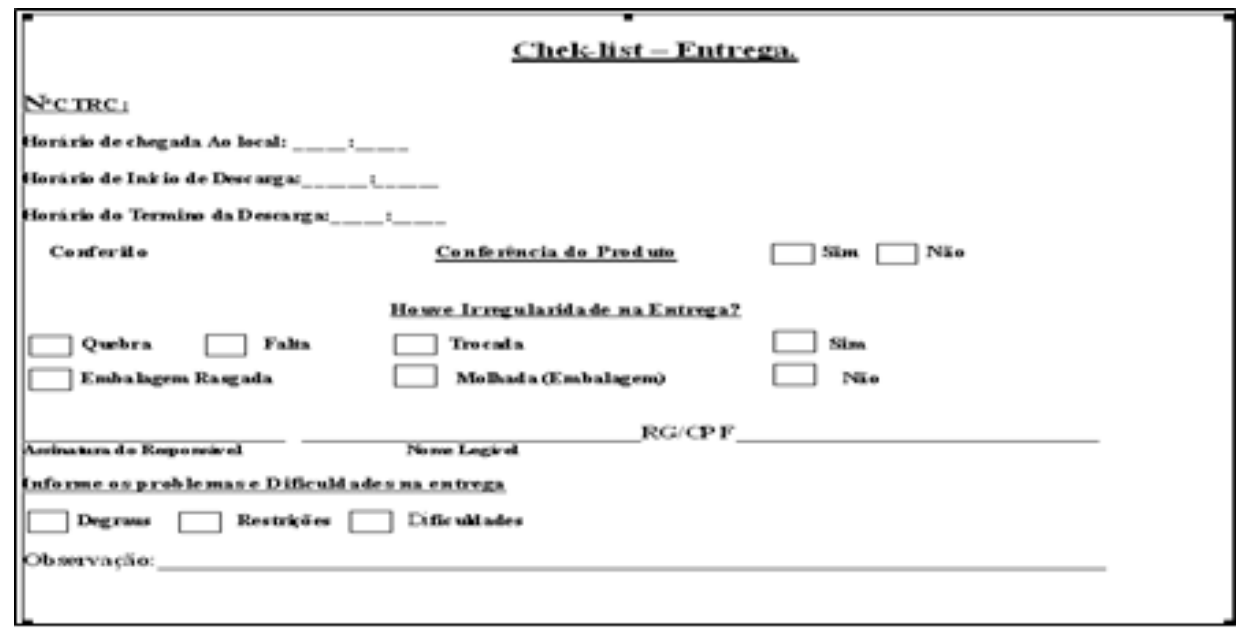

